\title{
From Guest-Editors of the Issue
}

DOI: $10.1134 / \mathrm{S} 1023193509010017$

This issue is collected in memoria Boris V. Ershler, an outstanding researcher whose Centenary was celebrated September 4, 2008. The contribution of B.V. Ershler to electrochemistry cannot be overestimated. To some extent, he was a maker of the electrochemistry of XX century, when the kinetics of electrode processes and its connection with the electrical double layer structure came to the forth.

The number of publication cannot be a merit of scientific inheritance of B.V. Ershler, it is rather modest. However, his studies in the electrochemistry are of enormous importance. Practically, each publication of B.V. Ershler was dedicated to fundamental problems that were a matter of principle; it opened new ways in the electrochemistry. B.V. Ershler was both theorist and skilled experimenter. He must be given the credit of experimentally corroboration of the basic concept of the slow discharge theory; namely, he proved the finiteness of the charge transfer rate and measured the rate of this process that distinguishes electrochemistry from all other branches of chemical science. When solving this problem, he developed the ac method that laid foundations of the modern electrochemical impedance spectroscopy. The very name of Ershler is immortalized in the name of the principal electrochemical equivalent circuit modeling the charge transfer, with due allowance of the electrical double layer capacitance and the reactantsí diffusion transfer.

B.V. Ershler developed an ingenious method of the studying of the electrical double layer structure at surfaces of smooth electrodes; he experimentally substantiated the adsorption theory of passivity with the taking into consideration the effect of electrical double layer on the electrode kinetics; he practically shut down (partly in collaboration with V.A. Pleskov) the problem of absolute potential in the electrochemistry.
The papers of this Issue present the continuation and advancement of the Ershlerís works. They mainly relate to the development and current applying of the electrochemical impedance spectroscopy. J.H. Sluyters discusses the applicability of the impedance method for mechanistic studies of electrode reactions. Other papers are dedicated to the using of the electrochemical impedance spectroscopy in the studies of particular processes. Such are papers of N.G. Bukun and A.E. Ukshe on the impedance of electrochemical systems with solid electrolyte; of T. Pajkossy and D.M. Kolb on the impedance of individual face of iridium single crystal; of T.L. Kulova, V.A. Tarnopolískii, and A.M. Skundin on the impedance of lithium-ion batteries; of V.V. Elkin on the impedance of processes with partial charge transfer. In the paper of M.D. Krotova, Yu.V. Pleskov, V.V. Elkin, A.D. Bozhko, and M.L. Shupegin, the method of the electrochemical impedance spectroscopy is used for the nanocomposite characterization. The papers "Thermodynamics of Surface Elasticity" by G. Paasch and B.M. Grafov and "The Relation between the Potential of Zero Charge and Work Function for $s p$-Metals" by V.V. Emets and B.B. Damaskin present the further development of the ideas on the electrical double layer structure.

The Issue is anticipated with the scientific biography of B.V. Ershler. It is written by B.V. Byakov, a disciple and closest collaborator of B.V. Ershler in the Institute of Theoretical and Experimental Physics; G.V. Steinberg, B.V. Ershlerís sister and noted expert in electrochemistry and chemical power sources; M.L. Ezerskii and A.M. Skundin who devoted many years to the history of Russian electrochemistry.

A. M. Skundin and Yu. V. Pleskov 